\title{
PENERAPAN METODE LOGIKA FUZZY MODEL TAHANI DALAM PEMILIHAN HARDWARE KOMPUTER
}

\author{
Moh. Heri Setiawan ${ }^{1} \S$, G. K. Gandhiadi ${ }^{2}$, Luh Putu Ida Harini ${ }^{3}$ \\ ${ }^{1}$ Jurusan Matematika, FMIPA - Universitas Udayana [Email: smohheri@ gmail.com] \\ ${ }^{2}$ Jurusan Matematika, FMIPA - Universitas Udayana [Email: gandhiadigk@ yahoo.com] \\ ${ }^{3}$ Jurusan Matematika, FMIPA - Universitas Udayana [Email: ballidah@unud.ac.id] \\ $\S$ Corresponding Author
}

\begin{abstract}
This study to determine the selection of computer hardware using fuzzy database method. This is because of many series of hardware produced by the manufacture, so the public will be confused in determining the choice of a combination of computer assembly. In this study the processor, motherboard, random access memory, hard disk, vga cards, power supply studied to find best recommendation. The result obtained from this study these several results obtained in study in the form of recommendation, that is if the recommendation value 0 then the hardware is not displayed as a decision, whereas if the recommendation value is greater than 0 and less than or equal to 1 the device will be displayed as a decision according to the value of its recommendation.
\end{abstract}

Keywords: Fuzzy Database, Tahani Model, Hardware, Personal Computer, Decision Support System

\section{PENDAHULUAN}

Seiring perkembangan zaman, perangkat keras komputer mengeluarkan produk-produk terbaru dengan spesifikasi perangkat keras yang lebih baru. Hal ini mengakibatkan seorang konsumen yang belum memiliki pengalaman dalam merakit komputer akan merasa bingung bila dihadapkan dengan pilihan perangkat keras yang ada.

Konsumen dalam pemilihannya akan memberikan kriteria-kriteria yang masih ambigu. Teori fuzzy dapat menangkap keambiguan dari kriteria yang diberikan konsumen. Salah satu metode fuzzy yang dapat digunakan dalam pencarian adalah basis data fuzzy model tahani.

Basis data merupakan gabungan file data yang dibentuk berdasarkan hubungan/relasi yang logis dan dapat diungkapkan dengan suatu catatan serta bersifat independen. Sistem basis data adalah suatu sistem penyusunan dan pengelolaan record-record dengan menggunakan komputer, dengan tujuan untuk menyimpan atau merekam serta memelihara data secara lengkap pada sebuah organisasi/perusahaan, sehingga mampu menyediakan informasi yang optimal yang diperlukan pemakai untuk kepentingan proses pengambilan keputusan (Lubis, 2016).

Sistem pendukung keputusan ini dapat digunakan untuk membantu pengambilan keputusan dalam situasi semi terstruktur dan tak terstruktur, dimana tak seorangpun yang secara pasti tidak dapat memberikan keputusan yang seharusnya dibuat (Turban, et al., 2001).

Pada penelitian ini akan mencoba menggunakan basis data fuzzy model Tahani dalam memberikan keputusan pemilihan perangkat keras komputer. Adapun perangkat keras yang dimaksud dalam penelitian ini adalah processor, motherboard, RAM, VGA card, harddisk, dan power supply.

\section{METODE PENELITIAN}

Sumber data yang digunakan pada penelitian ini adalah data primer berupa daftar seri dari setiap perangkat beserta harga dan spesifikasinya, sedangkan teknik pengumpulan 
datanya adalah observasi, wawancara, dan studi literatur.

Sistem fuzzy dalam penelitian ini meliputi kebutuhan input dari variabel processor, motherboard, RAM, VGA card, harddisk, dan power supply. Setiap variabel memiliki himpunan fuzzy sesuai dengan input yang dibutuhkan dalam sistem fuzzy.

Fungsi keanggotaan (membership function) adalah suatu kurva yang menunjukkan pemetaan titik-titik input data ke dalam nlai keanggotaannya (sering juga disebut dengan derajat keanggotaan) yang memiliki interval antara 0 sampai 1 . Salah satu cara yang dapat digunakan untuk mendapatkan nilai keanggotaan adalah dengan melalui pendekatan fungsi (Kusumadewi \& Purnomo, 2010).

Fungsi keanggotan dalam sistem fuzzy merupakan fungsi keanggotaan kombinasi antara fungsi kurva bahu kiri, kurva segitiga, dan kurva bahu kanan. Domain dari masingmasing fungsi dimulai dari 0 sampai dengan $\infty$ (tak hingga), hal ini karena agar domain dari fungsi lebih fleksibel.

Fuzzy Inference Sistem (FIS) merupakan sistem penarikan kesimpulan dari sekumpulan kaidah fuzzy/aturan fuzzy (Kusumadewi \& Purnomo, 2010). Pada penelitian ini hasil dari FIS akan menentukan nilai dari rekomendasi dari perangkat keras yang bersangkutan.

\section{HASIL DAN PEMBAHASAN}

Kebutuhan sistem fuzzy dari setiap variabel adalah sebagai berikut :

a. Kebutuhan input fuzzy variabel processor meliputi harga, kecepatan, core, dan tahun.

b. Kebutuhan sistem fuzzy variabel motherboard meliputi harga, slot RAM, kapasitas RAM, kecepatan maksimal RAM, dan tahun.

c. Kebutuhan sistem fuzzy variabel RAM meliputi harga, kecepatan, dan kapasitas.

d. Kebutuhan sistem fuzzy variabel VGA card meliputi harga, memory, kecepatan memory, kecepatan core, dan interface.

e. Kebutuhan sistem fuzzy variabel harddisk meliputi harga, kecepatan, dan kapasitas. f. Kebutuhan sistem fuzzy variabel power supply meliputi harga dan daya.

Fungsi keanggotaan dari setiap variabel fuzzy menggunakan kombinasi kurva bahu kiri, kurva segitiga, dan kurva bahu kanan untuk himpunan yang memiliki 3 himpunan fuzzy, sedangkan yang memiliki 2 himpunan fuzzy menggunakan kombinasi kurva bahu kiri dan kurva bahu kanan. Domain dari fungsi keanggotaan dari setiap variabel disajikan pada tabel berikut :

Tabel 3.1 Domain Fungsi Keanggotaan Variabel Processor

\begin{tabular}{|l|l|c|l|}
\hline \multicolumn{2}{|l|}{ Himpunan Fuzzy } & Domain & Satuan \\
\hline \multirow{3}{*}{ Harga } & Murah & {$[0,1370]$} & Rupiah \\
& Sedang & {$[695,2325]$} & $\begin{array}{c}\text { (dalam } \\
\text { ribuan) }\end{array}$ \\
\cline { 2 - 3 } & Mahal & {$[1370, \infty]$} & rian \\
\hline \multirow{3}{*}{ Core } & Sedikit & {$[0,4]$} & \multirow{3}{*}{ Buah } \\
\cline { 2 - 3 } & Sedang & {$[2,6]$} & \\
\cline { 2 - 3 } & Banyak & {$[4, \infty]$} & \\
\hline \multirow{3}{*}{ Kecepatanun } & Lambat & {$[0,2.5]$} & \multirow{3}{*}{ GHz } \\
\cline { 2 - 3 } & Sedang & {$[1.6,3.1]$} & \\
\cline { 2 - 3 } & Cepat & {$[2.5, \infty]$} & \\
\hline \multirow{3}{*}{ Tahun } & Lama & {$[0,2013]$} & \multirow{3}{*}{ Tahun } \\
\cline { 2 - 3 } & Sedang & {$[2012,2016]$} & \\
\cline { 2 - 3 } & Baru & {$[2013, \infty]$} & \\
\hline
\end{tabular}

Sumber: Data olahan tahun 2017

Tabel 3.2 Domain Fungsi Keanggotaan Variabel Motherboard

\begin{tabular}{|c|c|c|c|}
\hline \multicolumn{2}{|c|}{ Himpunan Fuzzy } & Domain & Satuan \\
\hline \multirow{3}{*}{ Harga } & Murah & {$[0,989]$} & \multirow{3}{*}{$\begin{array}{l}\text { Rupiah } \\
\text { (dalam } \\
\text { ribuan) }\end{array}$} \\
\hline & Sedang & {$[827.5,2085]$} & \\
\hline & Mahal & {$[989, \infty]$} & \\
\hline \multirow{3}{*}{ Tahun } & Lama & {$[0,2015]$} & \multirow{3}{*}{ Tahun } \\
\hline & Sedang & {$[2013,2016]$} & \\
\hline & Baru & {$[2015, \infty]$} & \\
\hline \multirow{3}{*}{$\begin{array}{l}\text { Max } \\
\text { Speed } \\
\text { RAM }\end{array}$} & Lambat & {$[0,2133]$} & \multirow{3}{*}{$\mathrm{MHz}$} \\
\hline & Sedang & {$[1866,2400]$} & \\
\hline & Cepat & {$[2133, \infty]$} & \\
\hline \multirow{2}{*}{$\begin{array}{l}\text { Slot } \\
\text { RAM }\end{array}$} & Sedikit & {$[0,4]$} & \multirow{2}{*}{ Buah } \\
\hline & Banyak & {$[2, \infty]$} & \\
\hline \multirow{3}{*}{$\begin{array}{l}\text { Max } \\
\text { RAM }\end{array}$} & Sedikit & {$[0,32]$} & \multirow{3}{*}{ GB } \\
\hline & Sedang & {$[16,64]$} & \\
\hline & Banyak & {$[32, \infty]$} & \\
\hline
\end{tabular}

Sumber: data olahan tahun 2017 
Tabel 3.3 Domain Fungsi Keanggotaan Variabel RAM

\begin{tabular}{|l|l|c|l|}
\hline \multicolumn{2}{|l|}{ Himpunan Fuzzy } & Domain & Satuan \\
\hline \multirow{3}{*}{ Speed } & Lambat & {$[0,1600]$} & \multirow{3}{*}{ MHz } \\
\cline { 2 - 3 } & Sedang & {$[1333,2133]$} & \multirow{2}{*}{ MHz } \\
\cline { 2 - 3 } & Cepat & {$[1600, \infty]$} & \\
\hline \multirow{3}{*}{ Harga } & Murah & {$[0,405]$} & Rupiah \\
& Sedang & {$[305,776]$} & (dalam \\
& ribuan) \\
\cline { 2 - 3 } & Mahal & {$[405, \infty]$} & \multirow{3}{*}{ GB } \\
\hline \multirow{3}{*}{ Kapasitasa } & Sedikit & {$[0,4]$} & \\
\cline { 2 - 3 } & Sedang & {$[2,8]$} & \\
\cline { 2 - 3 } & Banyak & {$[4, \infty]$} & \\
\hline
\end{tabular}

Sumber: data olahan tahun 2017

Tabel 3.4 Domain Fungsi Keanggotaan Variabel VGA Card

\begin{tabular}{|c|c|c|c|}
\hline \multicolumn{2}{|c|}{ Himpunan Fuzzy } & Domain & Satuan \\
\hline \multirow{3}{*}{$\begin{array}{l}\text { Core } \\
\text { Speed }\end{array}$} & Lambat & {$[0,1119]$} & \multirow{3}{*}{$\mathrm{MHz}$} \\
\hline & Sedang & [941,1260] & \\
\hline & Cepat & {$[1119, \infty]$} & \\
\hline \multirow{3}{*}{ Harga } & Murah & {$[0,1755]$} & \multirow{3}{*}{$\begin{array}{l}\text { Rupiah } \\
\text { (dalam } \\
\text { ribuan) }\end{array}$} \\
\hline & Sedang & {$[889.25,4417.5]$} & \\
\hline & Mahal & {$[1755, \infty]$} & \\
\hline \multirow{3}{*}{$\begin{array}{c}\text { Memory } \\
\text { Speed }\end{array}$} & Lambat & {$[0,5205]$} & \multirow{3}{*}{$\mathrm{MHz}$} \\
\hline & Sedang & {$[1800,7003]$} & \\
\hline & Cepat & {$[5205, \infty]$} & \\
\hline \multirow{2}{*}{ Interface } & Kecil & {$[0,256]$} & \multirow{2}{*}{ Bit } \\
\hline & Besar & {$[128, \infty]$} & \\
\hline \multirow{3}{*}{ Memory } & Sedikit & {$[0,4]$} & \multirow{3}{*}{ GB } \\
\hline & Sedang & {$[2,8]$} & \\
\hline & Banyak & {$[4, \infty]$} & \\
\hline
\end{tabular}

Sumber: data olahan tahun 2017

Tabel 3.5 Domain Fungsi Keanggotaan Variabel Harddisk

\begin{tabular}{|c|c|c|c|}
\hline \multicolumn{2}{|c|}{ Himpunan Fuzzy } & Domain & \multirow{4}{*}{$\begin{array}{l}\text { Satuan } \\
\text { Rupiah } \\
\text { (dalam } \\
\text { ribuan) }\end{array}$} \\
\hline \multirow{3}{*}{ Harga } & Murah & {$[0,995]$} & \\
\hline & Sedang & {$[609,1482.5]$} & \\
\hline & Mahal & {$[1042.5, \infty]$} & \\
\hline \multirow{3}{*}{ Kapasitas } & Kecil & {$[0,2000]$} & \multirow{3}{*}{ GB } \\
\hline & Sedang & {$[750,3000]$} & \\
\hline & Besar & {$[2000, \infty]$} & \\
\hline \multirow{2}{*}{ Kecepatan } & Lambat & {$[0,7200]$} & \multirow{2}{*}{ RPM } \\
\hline & Cepat & {$[5900, \infty]$} & \\
\hline
\end{tabular}

Sumber: data olahan tahun 2017
Tabel 3.6 Domain Fungsi Keanggotaan Variabel Power Supply

\begin{tabular}{|l|l|l|l|}
\hline \multicolumn{2}{|l|}{ Himpunan Fuzzy } & Domain & Satuan \\
\hline \multirow{4}{*}{ Daya } & Kecil & {$[0,650]$} & \\
\cline { 2 - 3 } & Sedang & {$[500,780]$} & \multirow{2}{*}{ Watt } \\
\cline { 2 - 3 } & Besar & {$[650, \infty]$} & \\
\hline \multirow{4}{*}{ Harga } & Murah & {$[0,1210]$} & \\
\cline { 2 - 3 } & Sedang & {$[640,1785]$} & \multirow{2}{*}{ Rupiah } \\
\cline { 2 - 3 } & Mahal & {$[1210, \infty]$} & \\
\hline
\end{tabular}

Sumber: data olahan tahun 2017

Aturan fuzzy dalam sistem ini menggunakan fungsi implikasi monoton dengan input himpunan dan operator bersifat dinamis untuk menentukan nilai fire-strengh dari implikasi. Sifat dinamis yang dimaksud adalah aturan fuzzy terbentuk sesuai dengan kombinasi yang diinginkan oleh pengguna. Fuzzy inference system yang terbentuk dari aturan fuzzy akan disesuaikan berdasarkan jumlah kriteria yang diinginkan oleh pengguna. Berikut aturan fuzzy berdasarkan jumlah kriteria yang diinginkan pengguna :

1. Dua kriteria dengan 1 operator

Fungsi implikasi dua kriteria dengan 1 operator adalah sebagai berikut :

$$
\begin{gathered}
I F \\
\left(x_{1} \text { is } A_{1}\right) O\left(x_{2} \text { is } A_{2}\right) \\
\text { THEN } y \text { is } B
\end{gathered}
$$

Dengan penentuan nilai fire-strengh untuk rekomendasinya adalah :

$$
\begin{gathered}
\mu_{\left(\mathrm{x}_{1} O x_{2}\right)}= \\
O\left(\mu_{x_{1}}\left[A_{1}\right], \mu_{x_{2}}\left[A_{2}\right]\right)
\end{gathered}
$$

2. Tiga kriteria dengan 2 operator

Fungsi implikasi tiga kriteria dengan 2 operator adalah sebagai berikut :

$$
\left.\begin{array}{c}
I F \\
\left(\left(x_{1} \text { is } A_{1}\right) O_{1}\left(x_{2} \text { is } A_{2}\right)\right) \\
O_{2}\left(x_{3} \text { is } A_{3}\right) \\
\text { THEN y is } B
\end{array}\right)
$$

Dengan penentuan nilai fire-strengh untuk rekomendasinya adalah :

$$
\begin{gathered}
\mu_{\left(\left(x_{1} o_{1} x_{2}\right) o_{2} x_{3}\right)}= \\
O_{2} \\
\left(O_{1}\left(\mu_{x_{1}}\left[A_{1}\right], \mu_{x_{2}}\left[A_{2}\right]\right), \mu_{x_{2}}\left[A_{3}\right]\right)
\end{gathered}
$$


3. Empat kriteria dengan 3 operator

Fungsi implikasi empat kriteria dengan 3 operator adalah sebagai berikut :

$$
\begin{gathered}
I F \\
\left(\begin{array}{c}
\left(\left(x_{1} \text { is } A_{1}\right) O_{1}\left(x_{2} \text { is } A_{2}\right)\right) \\
\left.O_{2}\left(x_{3} \text { is } A_{3}\right)\right) O_{3}\left(x_{4} \text { is } A_{4}\right)
\end{array}\right) \\
\text { THEN } y \text { is } B
\end{gathered}
$$

Dengan penentuan nilai fire-strengh untuk rekomendasinya adalah :

$$
\begin{gathered}
\mu_{\left(\left(x_{1} O_{1} x_{2}\right) o_{2}\left(x_{3} O_{3} x_{4}\right)\right)}=O_{3} \\
O_{2} \\
\left(\begin{array}{c}
O_{1} \\
\left(\mu_{x_{1}}\left[A_{1}\right], \mu_{x_{2}}\left[A_{2}\right]\right), \\
\left(\mu_{x_{3}}\left[A_{3}\right]\right) \\
\mu_{x_{4}}\left[A_{4}\right]
\end{array}\right),
\end{gathered}
$$

4. Lima kriteria dengan 4 operator

Fungsi implikasi lima kriteria dengan 4 operator adalah sebagai berikut :

$$
\left(\left(\left(\begin{array}{c}
\left(\left(x_{1} \text { is } A_{1}\right) O_{1}\left(x_{2} \text { is } A_{2}\right)\right) \\
O_{2} \\
\left(x_{3} \text { is } A_{3}\right) \\
O_{3}\left(x_{4} \text { is } A_{4}\right) \\
O_{4} \\
\left(x_{5} \text { is } A_{5}\right) \\
\text { THEN y is } B
\end{array}\right)\right.\right.
$$

Dengan penentuan nilai fire-strengh untuk rekomendasinya adalah :

$$
\begin{aligned}
& \mu_{\left(\left(\left(x_{1} O_{1} x_{2}\right) o_{2}\left(x_{3} O_{3} x_{4}\right)\right) o_{4} x_{5}\right)}= \\
& \mathrm{O}_{4}\left(\left(\begin{array}{c}
O_{3} \\
\left.O_{2}\left(\mu_{x_{1}}\left[A_{1}\right], \mu_{x_{2}}\left[A_{2}\right]\right)\right), \\
\mu_{x_{3}}\left[A_{3}\right] \\
\mu_{x_{4}}\left[A_{4}\right]
\end{array}\right)\right), \\
& \left.\mu_{x_{5}}\left[A_{5}\right]\right)
\end{aligned}
$$

dengan :

$$
\begin{array}{rll}
x_{i} & = & \text { kriteria ke-i } \\
A_{i} & = & \text { Himpunan fuzzy ke-i } \\
y & = & \text { Fire-strenght } \\
B & = & \text { Rekomendasi } \\
O_{i} & = & \text { Operator ke-i (AND }= \\
& & \text { min, OR }=\max )
\end{array}
$$

Sistem yang telah dibuat disimulasikan menggunakan data processor dengan spesifikasi sebagai berikut :

$\begin{array}{lll}\text { Harga } & : & \text { IDR } 1.440 .000 \\ \text { Kecepatan } & : & 3.5 \mathrm{GHz} \\ \text { Core } & : & 2 \\ \text { Tahun } & : & 2014\end{array}$

Dengan aturan fuzzy sebagai berikut :

- Jika Harga Sedang AND Kecepatan Cepat THEN Rekomendasi

Setelah mengetahui nilai input dari data tersebut diatas maka akan dicari derajat keanggotaan setiap himpunan yang diketahui sesuai dengan fungsi keanggotaan dari variabel processor. Berikut penghitungan manualnya :

a. Derajat keanggotaan himpunan harga

$$
\begin{aligned}
\mu_{\text {HargaMurah }}[1440000] & =0 \\
\mu_{\text {Hargasedang }}[1440000] & =\frac{2325000-1440000}{955000} \\
& =0.9267 \\
\mu_{\text {Hargamahal }}[1440000] & =\frac{1440000-1370000}{955000} \\
& =0.073298
\end{aligned}
$$

b. Derajat keanggotaan himpunan core

$$
\begin{aligned}
& \mu_{\text {Coresedikit }}[2]=1 \\
& \mu_{\text {CoreSedang }}[2]=0 \\
& \mu_{\text {CoreBanyak }}[2]=0
\end{aligned}
$$

c. Derajat keanggotaan himpunan kecepatan

$$
\begin{aligned}
\mu_{\text {KecepatanLambat }}[3.5] & =0 \\
\mu_{\text {KecepatanSedang }}[3.5] & =0 \\
\mu_{\text {KecepatanCepat }}[3.5] & =1
\end{aligned}
$$

d. Derajat keanggotaan himpunan tahun

$$
\begin{aligned}
\mu_{\text {TahunLama }}[201 & =0 \\
\mu_{\text {Tahunsedang }}[2014] & =\frac{2016-2014}{3} \\
& =\frac{2}{3} \\
& =0.667 \\
\mu_{\text {TahunBaru }}[2014 & =\frac{2014-2013}{3} \\
& =\frac{1}{3} \\
& =0.333
\end{aligned}
$$

Berdasarkan penghitungan di atas data simulasi memiliki derajat keanggotaan tertinggi pada himpunan Harga Sedang, Core Sedikit, Kecepatan Cepat, dan Tahun Sedang dengan masing-masing nilainya adalah $0.9267,1,1$, dan 0.667 .

Ouput dari sistem adalah sebuah urutan data berdasarkan fire-strengh dari kriteriakriteria yang diberikan oleh pengguna. berikut beberapa contoh hasil pencarian berdasarkan kriteria dari pengguna: 


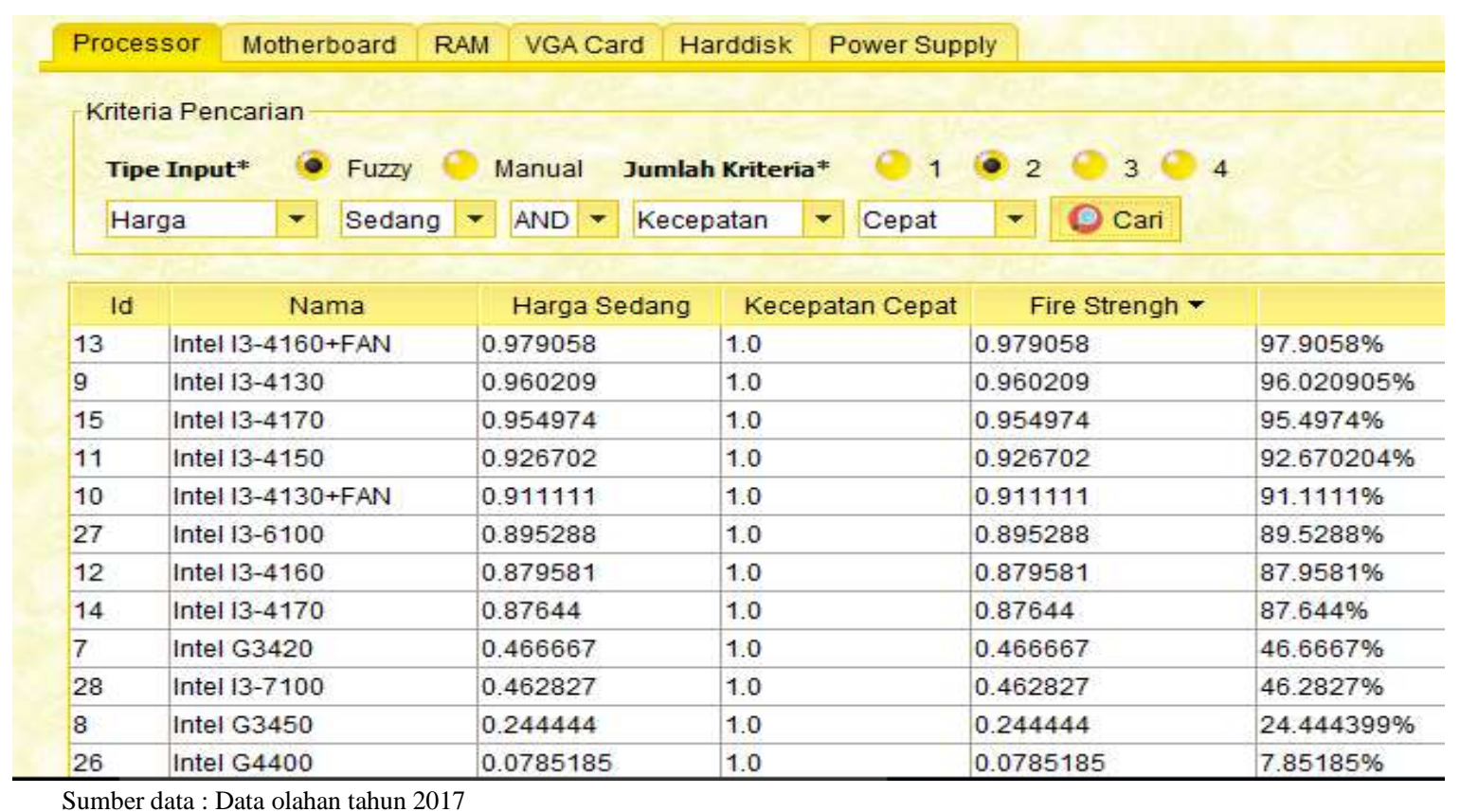

\section{Gambar 3.1 Output sistem}

Dari Gambar 3.1 dapat dilihat data simulasi yaitu Intel Core i3-4150 juga terbukti memiliki nilai rekomendasi $92.670204 \%$ dengan kriteria Harga Sedang dan Kecepatan Cepat, sesuai dengan perhitungan nilai rekomendasi secara manual.

\section{Kesimpulan dan Saran}

Penerapan metode basis data fuzzy dalam pemilihan perangkat keras komputer dapat memberikan rekomendasi pembelian perangkat keras sesuai dengan kriteria yang telah diberikan. Hal ini dapat dilihat dari nilai rekomendasi terhadap input maupun kriteria yang diberikan. Apabila nilai rekomendasi 0 maka perangkat keras tersebut tidak ditampilkan sebagai keputusan, sedangkan jika nilai rekomendasi lebih besar 0 dan kurang dari sama dengan 1 perangkat tersebut akan di tampilkan sebagai keputusan sesuai dengan nilai rekomendasi yang dimiliki perangkat tersebut.

Sistem pendukung keputusan pemilihan perangkat keras komputer ini masih dapat dikembangkan seiring dengan perkembangan perangkat keras komputer yang semakin tahun semakin berkembang. Oleh karena itu, disarankan untuk pengembangan sistem melalui penambahan kriteria setiap variabel sehingga dapat menambah kombinasi dalam pencarian oleh pengguna.

\section{DAFTAR PUSTAKA}

Kusumadewi \& Purnomo, 2010. Aplikasi Logika Fuzzy Untuk Pendukung Keputusan. Yogyakarta: Graha Ilmu.

Lubis, A., 2016. Basis Data Dasar Untuk Mahasiswa Ilmu Komputer. Yogyakarta: Deepublish.

Sparague, R. H. \& H., W. J., 1993. Decision Support Systems:Putting Theory Into Practice. Englewood Clifts, N. J.: Prentice Hall.

Turban, J. E., E. \& A., 2001. Decision Support Systems and Intelligent Systems 6th edition. Upper Saddle River New Jersey: Prentice Hall. 